\title{
Os pequenos nativos digitais e suas percepções sobre o mundo digital
}

\author{
Patrícia F. da Silva ${ }^{1}$, Léa da Cruz Fagundes ${ }^{2}$, Crediné S. de Menezes ${ }^{3}$ \\ ${ }^{1}$ PPGIE - Universidade Federal do Rio Grande do Sul (UFRGS) \\ Porto Alegre - RS - Brasil \\ ${ }^{2}$ PPGIE - Universidade Federal do Rio Grande do Sul (UFRGS) \\ Porto Alegre - RS - Brasil \\ ${ }^{3}$ Departamento de Estudos Básicos - Universidade Federal do Rio Grande do Sul \\ (UFRGS) / Porto Alegre - RS - Brasil \\ patriciasilva@lec.ufrgs.br, leafagundes@gmail.com, credine@gmail.com
}

\begin{abstract}
This article describes research a thesis research that is being developed in the Graduate Program in Computer Education at the Federal University of Rio Grande do Sul. Features an introduction, a brief account of the use of digital technologies by children in early childhood, the research methodology, as well as observations and interactions with the use of technological resources and finally the partial results of the study.
\end{abstract}

Resumo. Este artigo descreve uma pesquisa uma pesquisa de tese que vem sendo desenvolvida no Programa de Pós Graduação em Informática na Educação na Universidade Federal do Rio Grande do Sul. Apresenta uma introdução, um breve relato do uso das tecnologias digitais por crianças na primeira infância, a metodologia de pesquisa, bem como observações realizadas e as interações com o uso de recursos tecnológicos e por fim os resultados parciais do estudo.

\section{Introdução}

O avanço das tecnologias vem sendo impulsionado pelo desenvolvimento de ferramentas como internet móvel, touchscreen, wirelles, dentre outras, possibilitando que o manuseio com auxílio destes dispositivos seja cada vez mais fácil e intuitivo, não necessitando de um tutorial ou mesmo de uma explicação completa por parte dos usuários para acessá-los.

Por meio de um único equipamento portátil que comporta diversas mídias, é possível que os conteúdos educacionais, e não somente conteúdos, mas informações, revistas, artigos e aplicativos possam ser acessados a qualquer tempo e em qualquer lugar, e que estes estejam inseridos na rotina das pessoas.

Diante deste novo paradigma, se faz necessário estar atento à forma com que estas tecnologias estão sendo usadas e vistas pelas crianças, bem como a forma com que este mundo digital vem sendo percebido por ela.

Atualmente muito tem se ouvido falar sobre o uso de tecnologias digitais por crianças, diversas afirmações são realizadas sem pesquisa científica que comprove seu benefício ou malefício. 
O desenvolvimento educacional de crianças tem sido visto como aprender a ler e escrever, no entanto existem outras formas de aprender a ver o mundo a partir do uso de tecnologias, onde a criança possa testar ideias de forma autônoma utilizando regras e estruturas preestabelecidas, de modo que nenhum outro brinquedo proporcionaria (Papert, 2008).

O conhecimento inicia a partir das interações do sujeito com o objeto, e para assimilar as propriedades do objeto, existe a necessidade de realizar acomodações em seu sistema conceitual. Quando os esquemas disponíveis são insuficientes, a assimilação provoca perturbações, estas perturbações são ocasionadas pelo meio e fazem com que transformações internas aconteçam, buscando sempre se adaptar e melhorando seus níveis de adaptação, o que resulta em desenvolvimento de conhecimento (Piaget, 1987). Para que desequilíbrios aconteçam, a criança necessita sentir-se desafiada e instigada, através de situações que despertem a sua curiosidade e o desejo em aprender, para tanto, tendo em vista o crescente entusiasmo das crianças em relação ao uso das tecnologias digitais, esta parece ser uma boa alternativa.

Assim, através deste artigo, pretende-se apresentar os estudos preliminares que estão sendo desenvolvidos sobre: "O uso de tecnologias digitais com crianças de 5 meses a 7 anos - Há mudanças na gênese do pensamento operatório de crianças que começam a interagir com as tecnologias digitais na primeira infância?". Esta tem buscado observar se o uso e exploração do mundo digital pela criança se equivale em termos intelectuais à exploração de objetos reais.

Este artigo está organizado da seguinte forma: uso das tecnologias digitais por crianças, metodologia de pesquisa, observações realizadas e por fim uma análise com os resultados parciais obtidos até o momento.

\section{O uso das tecnologias digitais por crianças}

A cena de ver crianças explorando aparelhos de tecnologia móvel para entretenimento é cada vez mais comum, tendo em vista que muitas vezes os smartphones e tablets, são oferecidos pelos próprios pais, para que ela possa se distrair, ver seus vídeos, imagens ou explorar seus jogos favoritos.

O acesso às tecnologias digitais cada vez mais cedo, pode levar às crianças a uma nova perspectiva de aprendizagem, onde o contexto em que estão imersas, a facilidade para a obtenção destes equipamentos e a forma com que novas situações são apresentadas, venham favorecer o desenvolvimento intelectual e a autonomia.

Muito antes de se comunicar a criança já consegue se fazer entender e compreender os outros, "pois a competência linguística abrange tanto a capacidade das crianças para compreender a linguagem quanto sua capacidade para se fazerem entender" (BRASIL, 2001, p. 126).

Desde muito cedo há crianças em nossa sociedade que já possuem contato com os mais variados recursos tecnológicos, jogos, softwares e diferentes mídias. Vídeos, jogos on-line e aplicativos fazem parte do contexto diário e das brincadeiras favoritas.

A criança adquire conhecimento por meio daquilo que quer explorar, é dona da sua própria aprendizagem. Por mais que o adulto queira depositar conhecimento em seu caminho, ela pode escolher, determinando o que e como pensar. "O conhecimento é metabolizado, assimilado juntamente com todas as outras experiências diretas do mundo" (PAPERT, 2008, p. 24). 
O conhecimento necessário para as crianças será construído conforme o seu interesse, ou seja, o conhecimento irá ajuda-la a obter mais conhecimento, para isso, é preciso desenvolver formas de apoiar a criança a realizar a construção, bem como oferecer bons recursos, neste caso, as tecnologias digitais.

Atualmente, o uso de tecnologias digitais por crianças especialmente na primeira infância, ainda diverge opiniões, o uso aumentou muito nestes dois últimos anos, entretanto nenhuma pesquisa científica que embase os benefícios ou malefícios foi divulgada.

As informações que se têm até o presente momento baseiam-se na Neurociência. Para Almeida (2012), a infância é um período rico em sinapses, muito mais rico do que qualquer outro período de vida humano, mesmo a plasticidade cerebral ocorrendo em todas as fases da vida.

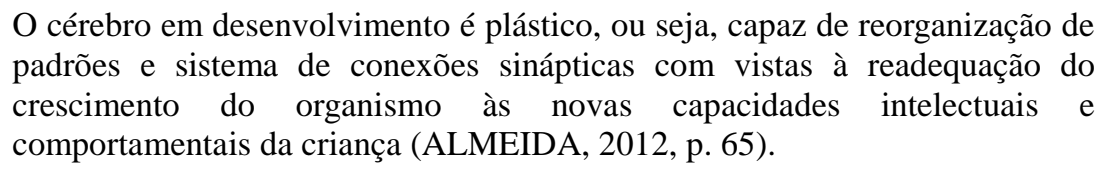

O cérebro em desenvolvimento é plástico, ou seja, capaz de reorganização de padrões e sistema de conexões sinápticas com vistas à readequação do crescimento do organismo às novas capacidades intelectuais e comportamentais da criança (ALMEIDA, 2012, p. 65).

Durante o período da infância, as células possuem uma maior capacidade para se adaptarem do que as células dos adultos, que já estão maduras, e por este motivo que com o passar da idade a plasticidade diminui e consequentemente é preciso um esforço maior para aprender. Isso não significa que quando adulto não se aprende, mas sim, que quando se é adulto é necessário um esforço maior, pois as vantagens naturais são perdidas (Almeida, 2012).

Diante do contexto atual, o uso de diferentes recursos tecnológicos pode ser um grande aliado para a construção de aprendizagem em crianças na primeira infância, tendo em vista que possuem potencial em relação aos estímulos cognitivos e também que pode ser utilizado em qualquer tempo e qualquer lugar.

\section{A metodologia de pesquisa}

O Método Clínico Piagetiano, vem sendo utilizado como forma de descobrir os aspectos do funcionamento e da estruturação da forma de pensar das crianças observadas no momento em que estão agindo sobre os objetos e por esta ação vão atribuindo sentido a eles, através dos seus atos.

Por meio deste método, busca-se analisar os mecanismos profundos do pensamento através da verificação da estrutura de um determinado estado de desenvolvimento ou dos processos de estruturação mental na resolução de um problema, a fim de compreender o que levou a criança a uma determinada resposta, possibilitando então a compreensão da problemática proposta (Delval, 2002).

Para Piaget, o Método Clínico permite conversar com o sujeito, seguindo-o em suas respostas de forma a nada perder. "A arte do clínico consiste não em fazer responder, mas em levar a falar livremente e em descobrir tendências espontâneas em vez de canalizá-las e barra-las. Consiste em situar todo sintoma num contexto mental em lugar de abstrair este contexto" (PIAGET, 2005, p.10).

A partir da observação de crianças da faixa etária de 5 meses a 7 anos de idade, estamos investigando se o mundo virtual está contribuindo em termos intelectuais para o desenvolvimento cognitivo das crianças e se o mundo digital faz com que ela perceba coisas que não consegue perceber no real. 
Para este estudo uma amostra de 14 crianças estão sendo observadas até o presente momento. Nestes encontros, foram observadas situações em que ela explorava seus brinquedos e realizava suas brincadeiras. Posteriormente eram colocadas diante de provas piagetianas ou então tentado verificar constatações realizadas por Piaget na obra "A formação do símbolo na criança" (1978). Na sequência, foram oferecidas situações de exploração de aplicativos com o uso de tablet ou smartphone, e por fim uma entrevista com os pais da criança para saber como estes têm percebido o uso das tecnologias digitais em seu contexto e no desenvolvimento cognitivo do seu filho.

\section{As observações realizadas}

Ao pesquisar com crianças desta faixa etária é preciso estar preparado muitas vezes para o imprevisível, pois nem sempre as observações acontecem conforme haviam sido planejadas e algumas vezes precisam ser modificadas para atender o interesse e a curiosidade da criança naquele momento.

Diante deste contexto, para dar início ao trabalho, primeiramente foi montado um quadro com aspectos a serem observados em cada uma das faixas etárias, concomitantemente com aspectos a serem explorados posteriormente com o uso das tecnologias digitais. As subseções a seguir descrevem uma breve contextualização dos níveis de desenvolvimento conforme Piaget (1977) e as características a serem observadas.

\subsection{Período sensório-motor}

O Período sensório motor ( 0 a 2 anos) caracteriza-se pela coordenação dos movimentos, percepções e ações entre si, estes que são reconstituídos pelo pensamento.

A inteligência acontece como um filme em câmera lenta, todas as ações são vistas, porém sem a composição da imagem, ou seja, sem a visão necessária para compor o conjunto. O pensamento nasce a partir da ação e é egocêntrico, a criança não procura a classificação ou a constatação, mas sim ao contentamento prático.

Por volta do final do segundo ano de vida, a criança começa a adquirir sistematicamente a linguagem, antes disso (últimos estágios do período sensório-motor), ela somente consegue imitar determinadas palavras e atribui a elas uma significação mais global. Este fato, se deve a utilização do sistema dos sinais verbais que são exercitados por uma "função simbólica" (Piaget 1976) mais geral, que permite representar o real através de "significantes" (parte ou aspecto objetivo do significado, causa e efeito) diferentes das coisas "significadas".

Para as crianças de 5 meses a 1 ano, as seguintes características foram levantadas para tentar identificar nos sujeitos observados: Percepção visual, repetições, primeiros condicionamentos, assimilação de gestos de outras pessoas, mover os lábios, colocar a língua para fora da boca, colocar o dedo na boca, franzir o nariz, comer, levar algo até a boca, cheirar. Já para as crianças da faixa etária de 1 a 2 anos: Percepção, atenção, motricidade fina, imitação, imitação mental (imitar por meio de lembranças).

\subsection{Período pré-operatório:}

O período pré-operatório ( 2 a 7 anos) é o primeiro período da inteligência préconceitual, caracteriza-se pelo pré-conceito a partir do aparecimento da linguagem até os 4 anos de idade. 
Os pré-conceitos são os primeiros elementos que a criança consegue relacionar, os "primeiros signos verbais" adquiridos por ela. Estes esquemas permanecem sempre como um meio termo entre o conceito generalizado e os elementos individuais que o constituem, mas não atinge nenhum deles. A criança ainda não consegue relacionar o que observou e situar o lugar ou tempo em que viu, nem as classes gerais "todo" e "alguns". Mais tarde, já consegue relacionar espaço distante e também reaparecimentos de situações espaçadas e diferentes.

O pensamento intuitivo progride em relação ao pensamento pré-conceitual ou simbólico no que se refere às formas de conjunto, a intuição permite levar ao estado inicial da lógica por meio de regulações representativas.

Para este período, nas crianças de 2 e 3 anos foram destacadas as seguintes características: Imitações, egocentrismo, jogo simbólico, valorização da pessoa imitada, atividades motoras, curiosidade, representação de um objeto ausente e linguagem (distinção de onde os objetos foram vistos).

Em crianças de 4 anos buscou-se observar Jogos simbólicos (declinação dos jogos simbólicos), egocentrismo, verbalização, linguagem (distinção de onde os objetos foram vistos, relação dos fatos), correspondências de tamanho, noção de tempo e descentrações do pensamento. Nas crianças de 5 e 6 anos, verbalização, grupamentos operatórios, ordem inversa (rotação de $90^{\circ}, 180^{\circ}, 270^{\circ}, 360^{\circ}$ ), noção de tempo e descentrações do pensamento.

Já para as de 7 anos, procurou-se observar a verbalização, ordem inversa (rotação de $90^{\circ}, 180^{\circ}, 270^{\circ}, 360^{\circ}$ ), noção de tempo, descentrações do pensamento, noções de inversão (trás para frente, esquerda, direita, rotações), relatos de explicações de movimentos de rios, nuvens, barcos utilizando como base movimentos físicos de atividades próprias e suas finalidades e grupamentos operatórios.

\section{As observações e aplicação das provas de Piaget x A exploração dos recursos tecnológicos}

Para iniciar as observações, foi disponibilizado um recado via Facebook e posteriormente contatada as famílias interessadas. Neste estudo, buscou-se a constituição de uma amostra com sujeitos de diferentes perfis, considerando: sexo, classe social, crianças que frequentam escolas de educação infantil e também crianças que ficam com suas mães.

Em geral, procura-se observar no mínimo duas crianças de cada faixa etária, em dois momentos diferentes. A realização das observações acontece na casa dos sujeitos, conforme a faixa etária, as características citadas anteriormente eram verificadas durante as brincadeiras realizadas pelas crianças. Para este artigo, são apresentadas algumas observações com crianças de diferentes faixas etárias, provas piagetianas e explorações com uso de tecnologias. Ao final da observação uma entrevista foi realizada com os pais para saber como que eles vêm percebendo as mudanças das tecnologias e se elas têm influenciado no desenvolvimento cognitivo dos seus filhos.

Para o primeiro sujeito, Cec 8 meses, foi observado se ela conseguia perceber o objeto quando escondido, para isso, um dos brinquedos utilizados por ela era escondido embaixo da sua fralda de pano. No primeiro momento ela não procurou o objeto, porém ao oferecer para ela um smartphone com uma programação em Scratch em que o gato corria de um lado para outro, miava, se escondia em uma das bolas, ela teve interesse em procurar o gato escondido. 


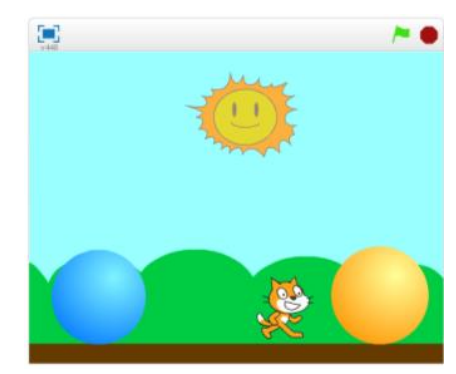

Figura 1. Captura de tela com a programação em Scratch

Ao pegar o smartphone com o auxílio da pesquisadora, a criança segura-o, olha a tela, mas não toca. A pesquisadora faz o gato se deslocar e ele mia, assim repete mais uma vez, até que o bebê agarra o aparelho querendo segurá-lo sozinho. Pegando nas mãos olha a tela, leva mais para perto dos olhos, vira ele de costas e depois de cabeça para baixo, após vira novamente com a tela para frente.

O segundo sujeito, Nic de 1 ano e 7 meses, foi pedido que ele imitasse alguns animais que estavam andando pelo sítio de sua avó. No campo estavam cavalos, galinhas, perus, bois e vacas. Nic $(1 ; 7)$ imitava os animais quando lhe era solicitado, porém era nítida a sua preferência pelo cavalo. Imitava-o e chamava com a mão, querendo ir sempre mais perto do animal.

Ao propor que ele interagisse com um recurso tecnológico, foi oferecido a ele o bichinho interativo da Totetoy Oody ${ }^{1}$, onde um aparelho de smartphone é colocado dentro de uma capa e explorado como um urso falante.

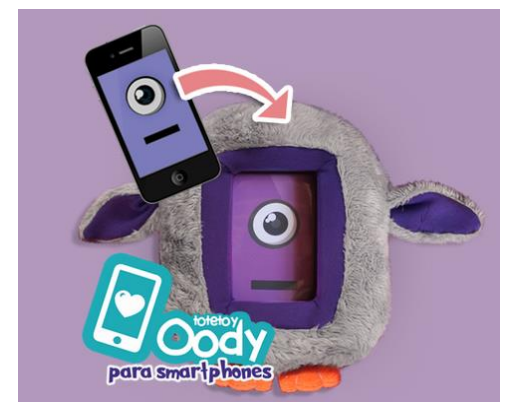

Figura 2. Imagem ilustrativa do bichinho interativo Oody

Nic $(1 ; 7)$ ao verificar que tocando no olho de Oody ele falava, Nic $(1 ; 7)$ sorriu e começou a apertar mais vezes. Oody iniciou falando: Cadê nenê?! Nic $(1 ; 7)$ se virou, olhou e sorriu, então apertou novamente ouvindo a fala do aplicativo: "- Me dá um abraço?!” Nic (1; 7), abraçou o bichinho, após apertou novamente: “- Beijo, beijo!" e ele beijou o bichinho.

O terceiro sujeito, Mar 2 anos foi observada em sua casa ao brincar encaixando peças de diferentes formas geométricas e mesmo tamanho em um brinquedo. Para iniciar a brincadeira, foi necessário convidá-la diversas vezes, até que ela aceitasse. A mesma conseguiu encaixar todas as peças sem dificuldades.

Ao propor que ela explorasse o recurso tecnológico, Mar (2;0) estava prontamente disposta a brincar. Foi apresentado para ela um smartphone com o

\footnotetext{
${ }^{1}$ Bichinho interativo para Smartphones totetoy.com.br
} 
V Congresso Brasileiro de Informática na Educação (CBIE 2016)

Anais dos Workshops do V Congresso Brasileiro de Informática na Educação (CBIE 2016)

aplicativo Classificação - Jogos para crianças ${ }^{2}$, a mesma iniciou a exploração com um pouco de dificuldades em arrastar as figuras para o seu lugar, porém em poucos instantes já conseguia conduzi-los e até mesmo verificar quando apresentavam diferenças de tamanho.

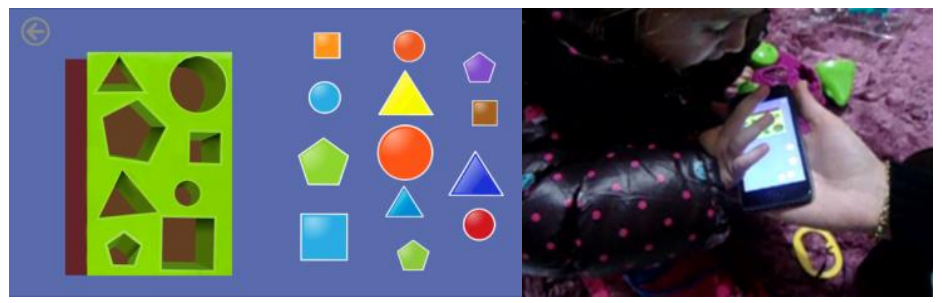

Figura 3. Imagem do aplicativo explorado e Mar $(2 ; 0)$ explorando o aplicativo

O quarto sujeito, Vic 4 anos e 6 meses aguardava a pesquisadora já com seu tablet para que novos aplicativos fossem instalados. Inicialmente foi pedido que ele relatasse como que se anda de gatinhas (engatinhar). - Você sabe como um bebê engatinha? - Sim, sei. - Como que é? Ele prontamente vai para o chão e mostra como se engatinha. - Você poderia me contar como que são os movimentos? O que acontece? Ah, Tem que dobrar uma perna aqui, depois a outra perna ali, e as mãos. - Você pode me mostrar com este urso? - Primeiro esta perna, depois a outra, aí as mãos! (Enquanto isso ele mostrava com o urso) - E quando você mostrou no chão, também era assim? - Sim!!

A exploração com o recurso tecnológico aconteceu com o uso do aplicativo Where's my water free ${ }^{3}$ no tablet. Vic $(4 ; 6)$ iniciou jogando e foram apresentadas as primeiras noções do jogo pelo próprio aplicativo. Após o mesmo foi questionado de como deveria proceder para que os demais níveis fossem alcançados, ele prontamente respondeu que deveria dar banho em Swampy e levar a água até o cano.

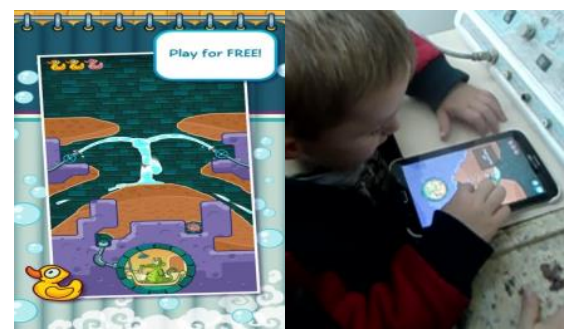

Figura 4. Imagem do aplicativo explorado e Vic $(4 ; 6)$ explorando o aplicativo

O quarto sujeito, Sar (6;3) estava olhando vídeos no Youtube com as músicas de Justin Bieber, para a observação foi solicitado que a mesma relatasse como acontece o processo de andar de gatinhas.

- Você sabe como um bebê engatinha? - Eu não sei. - Então pensa um pouquinho! Como que é? Quer fazer para lembrar? Bom! Ás vezes ele não consegue então a mamãe ajuda. - E como ele faz? - Ele coloca uma mão primeiro, daí ele coloca uma perna assim (ela estava mostrando com a perna oposta a mão que mostrou), depois coloca a outra mão e a outra perna, e ele vai fazendo. Aí ele começa a caminhar com a mãe, e aí depois começa a pegar o jeito de caminhar sozinho.

\footnotetext{
${ }^{2}$ Classificação - Jogos para crianças https://play.google.com/store/apps/details?id=com.andrey.sorterfree

${ }^{3}$ Where's um water free:

https://play.google.com/store/apps/details?id=com.disney.WMWLite\&hl=pt BR
} 
Após mostrei para ela o aplicativo Where's my water free ${ }^{4}$, no smartphone, ela já conhecia e conhecia também o do Mickey, questionei o quê precisava fazer para que ela avançasse de nível. - A gente tem que quebrar aonde vai certo até o cano. - Ao chegar ao nível 7, ela questionou como deveria baixar a tela, orientei como fazer e ela continuou jogando, sem conversar.

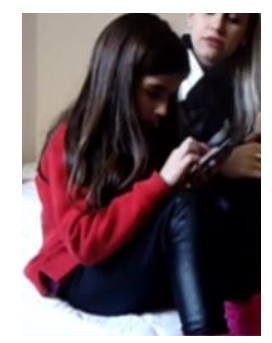

\section{Figura 5. Sar (6;3) explorando o aplicativo}

Questionei sobre qual a estratégia que ela estava usando para que passasse de nível. - Eu não sei muito bem! Mas tenho que remover as pedras até onde tem que ser. - E onde tem que ser? - Aqui! (me mostrou no jogo e passou de nível novamente).

\section{Análise das observações realizadas}

O primeiro sujeito observado, Cec $(0 ; 8)$ não atendeu ao teste em que o seu brinquedo foi tirado do seu campo visual, aquela situação, não despertou a sua atenção, a mesma agiu de forma indiferente como se realmente o objeto tivesse desaparecido.

Já ao ser apresentado um smartphone, Cec $(0 ; 8)$ mostrou-se atenta, prontamente olhou para ver o que acontecia e ouvia o som do gato miando de um lado para outro, após teve a iniciativa de querer pegar o objeto e segurá-lo sozinha, ao tê-lo em suas mãos, começou a procurar se o gato estava escondido em uma das bolas, para isso virou o aparelho e começou a olhar no seu arredor, embaixo e também atrás dele.

O Segundo sujeito, Nic $(1 ; 7)$ fazia as imitações conforme solicitado, porém nesta situação contamos um fator bastante relevante, ele podia observar os animais, mesmo assim, ele tinha uma preferência, imitava o cavalo mesmo quando era pedido que imitasse um outro animal.

Ao propor que Nic $(1 ; 7)$ interagisse com Oody, ele pareceu estar mais atento, olhava com atenção o olho que aparecia na tela e ele mesmo tocava para ouvir a próxima frase, e depois seguia as solicitações feitas pelo bichinho interativo. Percebeu também, que poderia trocar de tela e buscar por outras atividades neste mesmo aplicativo, porém a sua preferência era ver Oody falando.

O terceiro sujeito Mar (2;0), apresentava evidências de egocentrismo, sempre que questionada o brinquedo utilizado era de "Mar $(2 ; 0)$ "! Ao iniciar encaixando as peças no brinquedo, ela teve que ser convidada diversas vezes, não estava muito interessada em brincar. No entanto, ao apresentar o smartphone, não foi necessário falar mais de uma vez.

Mar $(2 ; 0)$ apresentou alguma dificuldade em movimentar a tela devido a tecnologia touchscreen, mas logo já dominou e começou a utilizar sozinha. Observou que as peças tinham diferentes tamanhos e também que apesar da mesma forma

\footnotetext{
${ }^{4}$ Where's um water free:

https://play.google.com/store/apps/details?id=com.disney.WMWLite\&hl=pt BR
} 
V Congresso Brasileiro de Informática na Educação (CBIE 2016)

Anais dos Workshops do V Congresso Brasileiro de Informática na Educação (CBIE 2016)

geométrica, não poderia encaixá-la se fosse maior ou menor que o espaço mostrado na tela.

O quarto sujeito, Vic $(4 ; 6)$ mostrou-se tímido durante a observação, falava pouco, mas respondia quando lhe era solicitado. Ao falar dos movimentos de andar de gatinhas, ele argumenta que a movimentação acontece em forma de " $Z$ ", conforme descrito por Piaget (1977), o que já era esperado para uma criança de 4 anos e meio. Porém ao pedir que ele explicasse o funcionamento do jogo, foi possível perceber maior desprendimento, uma assimilação do objeto explorado e posterior acomodação, pois através das suas jogadas Vic $(4 ; 6)$ conseguia explicar o jogo, como realizar as jogadas e o que fazer para avançar de nível, se evidenciando um processo de tomada de consciência (Piaget 1977).

No quinto sujeito Sar $(6 ; 3)$, o uso de recursos digitais é bem presente no seu cotidiano, a mesma se apropria dos recursos e os utiliza com ótima desenvoltura. Ao ser questionada sobre o processo de andar de gatinhas, Sar $(6 ; 3)$ ela conseguiu descrever com propriedade e corretamente o andar.

Conforme Piaget (1977), ela se encontra no estágio II B onde a criança descreve o andar em formato Z. Outro aspecto relevante, é que ela além de descrever o processo de andar de gatinhas, também descreveu como a criança inicia a andar.

\section{As primeiras evidências}

Durante as observações realizadas foi possível verificar o nítido interesse das crianças pelos aparelhos e pelas tecnologias digitais. O lúdico, o som, as cores, a possibilidade de jogar quantas vezes quiser, repetir fases e continuar de onde parou se mostram mais atrativas do que as provas Piagetianas.

As provas Piagetinas foram realizadas pelas crianças sem grandes diferenças em relação aos resultados apresentados pelos testes originais, com exceção de Sar $(6 ; 3)$ que conseguiu explicar o movimento de andar de gatinhas conforme crianças com de mais de 8 anos que já se encontram no nível IIB.

Diante dos recursos tecnológicos explorados, as crianças fizeram e perceberam determinadas coisas que com os objetos concretos e situações reais não fizeram, como por exemplo, Cec $(0 ; 8)$ que se interessou em procurar o gato escondido no smartphone e não o brinquedo em sua fralda de pano.

As tecnologias digitais possibilitaram que as crianças realizassem constatações mais aprofundadas do que nas provas Piagetianas, pois os recursos tecnológicos apresentados envolveram diferentes sentidos, bem como proporcionaram que elas descobrissem coisas sem terem que fazer um esforço tão grande como quando trabalham com objetos reais.

Com todos os sujeitos foi possível verificar uma ótima interação com os recursos digitais, através destes, diferentes situações foram apresentadas às crianças por meio da exploração e posteriormente assimiladas e acomodadas por seus sistemas conceituais. A exploração das tecnologias desencadeou nas crianças perturbações, que as conduziram a continuar explorando e tentar encontrar uma solução para o problema em questão.

Além de lúdico e atrativo, as tecnologias digitais proporcionaram que as crianças se envolvessem com um desafio a ser solucionado, interagindo e observando quais os aspectos que deveriam ser melhorados para que continuasse avançando de nível, 
V Congresso Brasileiro de Informática na Educação (CBIE 2016)

Anais dos Workshops do V Congresso Brasileiro de Informática na Educação (CBIE 2016)

realizando para isso frequentemente um processo chamado a tomada de consciência (Piaget, 1977), por meio das suas escolhas mais ou menos intencionais.

As crianças observadas, durante o uso das tecnologias digitais deixaram transparecer em diferentes momentos que precisavam buscar respostas para determinados níveis dos aplicativos, ou seja, sofriam perturbações, assimilavam e se desequilibravam, com a possibilidade de recupera-las, ocorrendo assim, o processo de reequilibração majorante.

Ao utilizar as tecnologias digitais com as crianças, implicações epistemológicas são desenvolvidas de forma mais rica e com as mesmas condições do que quando se trabalha com materiais usuais, ou seja, a criança está aprendendo a construir seu conhecimento través dos conhecimentos necessários para efetuar o que é solicitado, e não é apenas uma consumidora de equipamentos e tecnologias.

Uma série de conhecimentos sobre espaço, quantidade, tempo, lateralidade, oralidade e ainda a autonomia são desenvolvidos, elementos estes que serão essenciais para conhecimentos posteriores.

$\mathrm{O}$ mundo virtual mostrou-se mais atrativo porque possibilitou às crianças ter a oportunidade de aprender de modo não-formal, e sim fazendo e descobrindo sem seguir uma sequência definida.

\section{Referências}

Almeida, G. (2012) "Neurociência e sequência didática para a educação infantil”, Rio de Janeiro: Wak Editora, Julho.

Deval, J. (2002) "Introdução à prática do método clínico: descobrindo o pensamento das crianças", Porto Alegre: Artmed, Agosto.

Müller, C. (2015) "Uso das tecnologias ajuda ou atrapalha as crianças na escolar?" Entrevistador: http://www.sbp.com.br/saiu-na-imprensa/uso-de-tecnologias-ajudaou-atrapalha-as-criancas-na-escola/, Agosto.

Papert, S. (2008) "A máquina das crianças: repensando a escola na era da informática" Tradução Sandra Costa, ed. Ver. Porto Alegre, Artmed. Agosto.

Piaget, J. (1976) "A equilibração das estruturas cognitivas: problema central do desenvolvimento", Zahar Editores, Rio de Janeiro. Abril.

Piaget, J. (1977) "A tomada de consciência", com a colaboração de A. Blamchet [e outros] tradução de Edson Braga de Souza, São Paulo, Melhoramentos, Ed. Da Universidade de São Paulo. Agosto.

Piaget, J. (1978) “A formação do símbolo na criança: imitação, jogo e sonho, imagem e representação". Tradução de Álvaro Cbral e Christiano Monteiro Oiticica. Rio de Janeiro: Guanabara Koogan, Julho.

Piaget, J. (1988) "Psicologia e Epistemologia Genética". In: Ramozzi-Chiarottino, Zelda. São Paulo. Maio. 